\title{
Liver dynamics of HCV infection amongst patients aged 50 years or older visiting a larger tertiary care centre of Hyderabad, Pakistan
}

\begin{abstract}
Introduction: Usually chronic infection of hepatitis $\mathrm{C}$ virus $(\mathrm{HCV})$ is asymptomatic until present as acute hepatitis, acute liver failure or development of cirrhosis with decompensation. New era of Direct-acting antiviral (DAAs) for HCV has evolved the treatment with good result and tolerability. Early diagnosis and treatment can halt the further disease progression.

Methodology: In this cross sectional study, all the patients with HCV positive either acute or chronic hepatitis infection, cirrhoisis with or without decompensation, aged 50 year or above, of either gender, presenting in the outpatient department (OPD) were included.

Results: A total of 281 patients were enrolled during the study period. Mean age of the study population was $56.91 \pm 7.21$ years (range: $50-90$ years) and majority were male $(51.6 \%)$ and with Child class A 136 (48.4\%) followed by child class B 96(34.2\%). Majority of patients presented as decompensated cirrhosis and raised transamines 160 (56.9\%). Most common complication was variceal bleed $95(33.8 \%)$ followed by ascities $88(31.3 \%)$, pedal edema24 (8.5\%). More than half of the patients were not eligible for treatment. Correlation between age and gender with liver stage and comorbids was statically significant $(\mathrm{p}=0.001)$.

Conclusion: Late diagnosis present with complication with least options of treatment Chronic hepatitis $\mathrm{C}$ is curable disease and should be diagnosed as early as possible. There should be screening at younger age.
\end{abstract}

Keywords: hepatitis $\mathrm{C}$ virus, world health organization, hypertension, haematemesis
Volume 12 Issue 3 - 202 I

\author{
Jawaid lqbal,Abdul Hafeez Soomaro,Adil \\ Hassan, Muhammad Mashooque, Bushra \\ Qadir, Sidra Dars, Muhammad Sadik Memon \\ Department of Gastroenterology,Asian institute of Medical \\ science, Pakistan
}

\author{
Correspondence: Jawaid lqbal, Department of \\ Gastroenterology, Asian Institute of Medical and Science, \\ Hyderabad Pakistan, Tel +9233329185I I, \\ Email drjaved1982@yahoo.com
}

Received: November 15, 2019 | Published: May 03, 2021
Abbreviations: HCV, hepatitis C virus; DAAs, Direct-acting antiviral agents; WHO, world health organization; OPD, outpatient department

\section{Introduction}

Chronic infection of hepatitis $\mathrm{C}$ virus (HCV) is usually asymptomatic until it present as acute hepatitis, acute liver failure or development of cirrhosis with decompensation. The New era of Direct-acting antiviral agents (DAAs) for $\mathrm{HCV}$ has evolved the treatment with good result and tolerability. With the use of direct antiviral agents (DAAs) for chronic HCV infection our knowledge on the pathogenesis, clinical course and the treatment of HCV has increased.

In elderly patients chronic infection may be more severe and is said to be more prevalent. ${ }^{1}$ Early diagnosis and treatment can halt the further disease progression, damage of liver disease and death. Late diagnosis effects the treatment efficacy, cost and risk of continuous liver damage. Over 71 million people are affected globally with chronic HCV infection. ${ }^{2}$ This has enormous burden on the economy and health sector of any country. The World health organization (WHO) has set the goal to eliminate HCV infection from the world by the year $2030 .^{3,4}$

$\mathrm{HCV}$ is endemic in Pakistan and according to a national survey which was conducted in 2007-2008 and the prevalence of HCV is $4.8 \% .{ }^{5}$ Genotype $3 \mathrm{a}$ is most prevalent $\mathrm{HCV}$ variant in pakistan. ${ }^{6,7}$ Aim of our study is to determine the behavior of liver who diagnosed late with HCV infection.

\section{Patients and methods}

All consecutive patients with $\mathrm{HCV}$ positive either acute or chronic hepatitis or infection, cirrhoisis with or without decompensation, aged 50year or above, of either gender, presenting in the outpatient department(OPD) of Asian Institute of Medical and Science were included. Cirrhosis is a chronic degenerative disease in which normal liver cells are damaged and are then replaced by scar tissue. ${ }^{8}$ Decompensated cirrhosis was defined on radiological findings, history of haematemesis and/or clinical evidence of encephalopathy. Patients with less than fifty years of age were excluded from the study. After taking informed consent, blood sample for complete blood count, liver function tests, serum albumin, INR, viral serology and serum creatinine was collected.

\section{Results}

A total of 281 patients were enrolled during the study period. The Mean age of the study population was $56.91 \pm 7.21$ years (range: $50-90 y e a r s)$ and majority were male $(51.6 \%)$ and having Child class A 136 (48.4\%) followed by child class B 96(34.2\%) (Figure 1). Clinical characteristics and laboratory parameters of the study population are shown in Table 1. Majority of patients were from urban areas at district level 161(57.3\%) with sindhi ethnicity 176 $(62.6 \%)$ with poor education under primary $146(52.0 \%)$. More than half of the patients $129(45.9 \%)$ were not eligible for antiviral treatment for chronic HCV. In this population major comorbids were dyspepsia 205(73.0\%), hypertension 93(33.1\%), diabetes mellitus 68(24.2\%), chronic HBV 57(20.3\%) and Ischemic heart 
disease 21(7.5\%). Most common complication was variceal bleed 95(33.8\%) followed by ascities $88(31.3 \%)$, pedal edema with portal hypertension and hepatocellular carcinoma HCC 19(6.8\%). Most of the patients presented with common symptoms $79(28.1 \%)$ followed by routine screening $71(25.3 \%)$. Majority of patients presented as decompensated cirrhosis and raised transaminases $160(56.9 \%)$ as shown Table 2. Table 3 shows correlation between age and gender with liver stage and comorbids which shows significant correlation of male gender with comorbids and liver stage at the time of diagnosis.

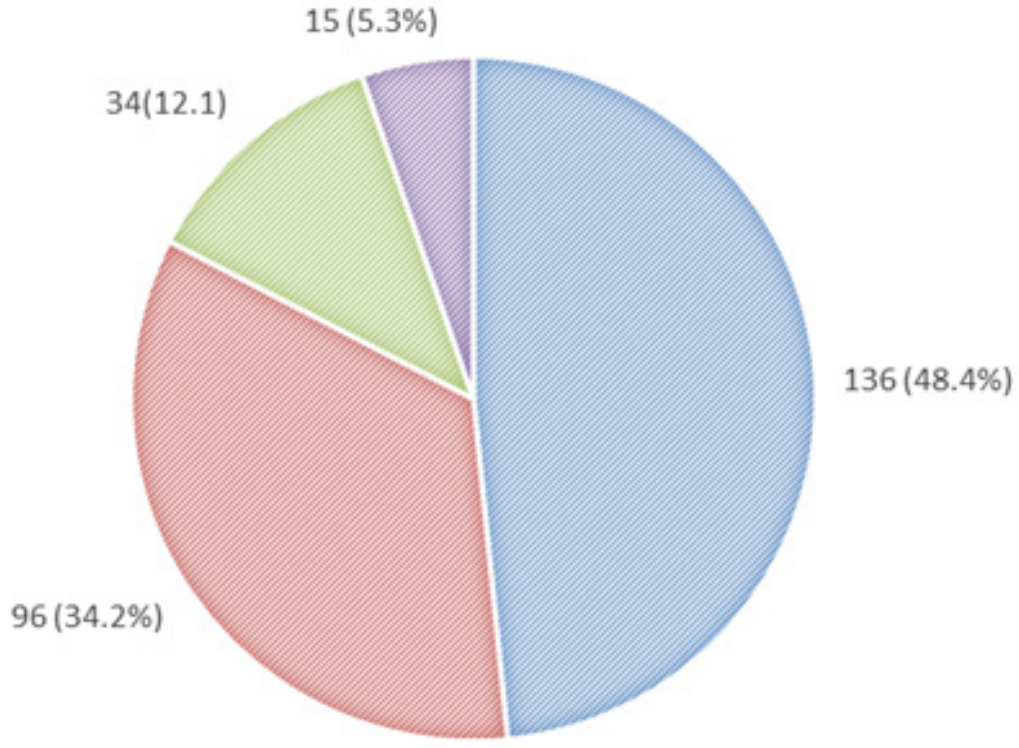

Figure I Child-Pugh Classification.

Table I Baseline characteristics, comorbid and complications

\begin{tabular}{lll}
\hline Variables & & Mean \pm SD / n (n\%) \\
\hline Age (years) & Male & $56.91 \pm 7.21$ \\
Gender & Female & $136(48.4)$ \\
& village & $145(51.6)$ \\
Residence & Tehsil & $34(12.1)$ \\
& District & $36(12.8)$ \\
& Division & $161(57.3)$ \\
& Uneducated & $50(17.8)$ \\
Education & Under Primary & $1(0.4)$ \\
& Primary & $146(52.0)$ \\
& Matric & $77(27.4)$ \\
& F.A & $32(11.4)$ \\
& graduate & $2(0.7)$ \\
& Sindhi & $23(8.2)$ \\
& Punjabi & $176(62.6)$ \\
& Urdu & $23(8.2)$ \\
& Pathan & $61(21.7)$ \\
& Oaloch & $17(6.0)$ \\
& Other & $10.4)$ \\
& & \\
& &
\end{tabular}




\begin{tabular}{ll}
\hline Table Continued... & Mean $\mathbf{E S D}$ / n (n\%) \\
\hline Variables & $129(45.9)$ \\
\hline Eligible for antiviral treatment & \\
Comorbid conditions & $205(73.0)$ \\
Dyspepsia & $93(33.1)$ \\
Hypertension & $68(24.2)$ \\
Diabetes & $57(20.3)$ \\
Hep B & $21(7.5)$ \\
Ischemic heart disease & \\
Common complications & $95(33.8)$ \\
Variceal Bleeding & $88(31.3)$ \\
Ascites /SBP & $40(14.2)$ \\
PSE & $24(8.5)$ \\
Only P. Edema +P,HTN & $19(6.8)$ \\
HCC & $6(2.1)$ \\
Liver failure & $5(1.8)$ \\
Others & $4(1.4)$ \\
Acute on CHC & \\
\hline
\end{tabular}

Age presented in mean standard deviation, categorical data presented in $\mathrm{n}(\mathrm{n} \%)$

Table 2 Different medium of $\mathrm{CHC}$ diagnosis, stages of the liver disease

\begin{tabular}{ll}
\hline How do you know about CHC? & $\mathbf{n}(\mathbf{n} \%)$ \\
\hline $\begin{array}{l}\text { Due to symptoms related CHC } \\
\text { (fatique, weakness, fever, etc.) }\end{array}$ & $79(28.1)$ \\
Routine screening & $71(25.3)$ \\
Due to complication & $67(23.8)$ \\
Due to symptoms of dyspepsia & $32(11.4)$ \\
Pre-operative screening & $17(6.0)$ \\
screening U/s abdomen & $8(2.8)$ \\
Pre transfusion & $4(1.4)$ \\
Other family members were found to have HBV/HCV & $2(.7)$ \\
Pre-vaccination screening & $1(.4)$ \\
Stages of liver disease & \\
CHC without cirrhosis & $105(37.4)$ \\
CHC-with normal ALT & $29(10.3)$ \\
CHC-increased ALT & $76(27.0)$ \\
CHC with cirrhosis & $160(56.9)$ \\
CHC-Normal ALT \& cirrhosis(compensated) & $17(6.0)$ \\
CHC-increased ALT \& cirrhosis(compensated) & $43(15.3)$ \\
CHC-Normal ALT \& decompensated cirrhosis & $20(7.1)$ \\
CHC-increased ALT \& decompensated cirrhosis & $80(28.5)$ \\
Others & $16(5.7)$ \\
CHC-HCC & $10(3.6)$ \\
CHC-acute or chronic Hepatitis "C"(altered mention) & $2(.7)$ \\
CHC- acute or chronic Hepatitis "C"(normal mention) & $\mathrm{I}(.4)$ \\
\hline & \\
\hline
\end{tabular}

Citation: lqbal J, Soomaro $\mathrm{AH}$, Hassan $\mathrm{A}$, et al. Liver dynamics of $\mathrm{HCV}$ infection amongst patients aged 50 years or older visiting a larger tertiary care centre of Hyderabad, Pakistan. Gastroenterol Hepatol Open Access. 202 I; I2(3):68-72. DOI: I0.15406/ghoa.202 I. 12.00458 
Table 3 Association between Age groups and Gender with Liver Stage and Comorbids

\begin{tabular}{|c|c|c|c|c|c|c|c|}
\hline & & \multicolumn{2}{|l|}{ Age group } & \multirow{2}{*}{-P-Value } & \multicolumn{2}{|l|}{ Gender } & \multirow[t]{2}{*}{ P-Value } \\
\hline & & $\leq 55$ years & $>55$ years & & Male & Female & \\
\hline & CHC without cirrhosis & $62(37.3 \%)$ & $43(37.4 \%)$ & & $40(29.4 \%)$ & $65(44.8 \%)$ & \\
\hline \multirow[t]{3}{*}{ Liver Stage } & CHC with cirrhosis & $95(57.2 \%)$ & $65(56.5 \%)$ & 0.970 & $82(60.3 \%)$ & $78(53.8 \%)$ & $0.001 *$ \\
\hline & Others & $9(5.4 \%)$ & $7(6.1 \%)$ & & $14(10.3 \%)$ & $2(1.4 \%)$ & \\
\hline & Diabetes & $45(27.1 \%)$ & $23(20.0 \%)$ & 0.170 & $35(25.7 \%)$ & $33(22.8 \%)$ & 0.560 \\
\hline \multirow[t]{2}{*}{ Comorbids } & Dyspepsia & I24(74.7\%) & $81(70.4 \%)$ & 0.430 & $83(61.0 \%)$ & $122(84.1 \%)$ & $0.001 *$ \\
\hline & HTN & $57(34.3 \%)$ & $36(31.3 \%)$ & 0.730 & $33(24.3 \%)$ & $60(41.4 \%)$ & $0.001 *$ \\
\hline
\end{tabular}

\section{Statistical analysis}

Statistical analysis was performed by SPSS (version 20.0). Mean and standard deviation were calculated for continuous variables, while frequencies and percentages were calculated for categorical variables. Spearman's correlation coefficient was calculated to document the strength of association between age, gender with liver stage and comorbids. $P<0.05$ was considered significant for association between gender with liver stage and comorbids in statistical analysis.

\section{Discussion}

Chronic hepatitis $\mathrm{C}$ is common hepatic infection worldwide and very endemic $4.8 \%$ in Pakistan. ${ }^{5} \mathrm{HCV}$ infection in childhood or younger age has high rate of $\mathrm{HCV}$ clearance than older age infected patients. ${ }^{9}$ Late diagnoses of $\mathrm{HCV}$ infection may result inflammation of hepatocytes followed by distortion of architecture and formation of regenerative nodules with end result cirrhosis of liver. ${ }^{10}$ The finding from this study suggest that behavior of liver on the basis of liver biomarkers, sonographic appearance and clinically may deteriorate with late diagnosis.

In this group majority of patients were female $145(51.6 \%)$ with low education under primary $146(52.0 \%)$. More than fifty percent of patients were not eligible for treatment at the time of diagnosis because of the complication and advance age. Male gender is strongly associated with liver stage and comorbids like dyspepsia.

Majority of our patients presented with cirrhosis 160(56.9\%) out of them $80(28.5 \%)$ were decompensated with raised ALT at the time of diagnosis while Seeff et al. and Watson et al. has reported that HCV infection with young adult presented without cirrhosis while older age with cirrhosis and advanced age presented with HCC., ${ }^{911}$ Majority of patients were investigated for constitutional symptoms like fatigue, weakness followed by routine screening and complication. Hassoun et al. ${ }^{12}$ also reported that patient with $\mathrm{HCV}$ infection age above 50 presented with fatigue. ${ }^{12}$

In our study liver stage is categorized in two groups, chronic hepatitis $\mathrm{C}$ with cirrhosis and without cirrhosis. Majority of our patients $(43.8 \%)$ were cirrhotic with raised ALT and $(27 \%)$ without cirrhosis with raised ALT in both groups as shown in Table 2. In our study population statically significant association was found between liver stage and comorbids like dyspepsia and hypertension based on gender but no significant association was found with age group after 50years as shown in Table 3. Toyoda et al. ${ }^{13}$ also addressed no significant association between age and severity of liver disease. Another study was conducted by Amina et al. ${ }^{14}$ which show no association between severity of liver disease based on age group and gender but in our study there is significant association $(\mathrm{P}=0.001)$ between liver stage and comorbids based on gender.
There are certain limitations in the study. These include its single center origin and small sample size. We also did not perform longitudinal follow-up of this cohort of patients and all the patients were at or above 50 years of age. Despite the above limitations, this study provides a basis for performing multicenter prospective study on a large number of patients.

\section{Conclusion}

Chronic hepatitis $\mathrm{C}$ is curable disease and should be diagnosed as early as possible before the development of complication. There should be screening for everyone as early as possible in the countries with intermediate to high prevalence of $\mathrm{HCV}$ infection. ${ }^{15}$

\section{Acknowledgments}

None.

\section{Conflicts of interest}

The authors declare that there are no conflicts of interest.

\section{Funding}

None.

\section{References}

1. High KP, Marcus EL, Tur-Kaspa R. Chronic hepatitis C virus infection in older adults. Clinical Infectious Diseases. 2005;41(11):1606-1612.

2. Spearman CW, Afihene M, Ally R, et al. Hepatitis B in sub-Saharan Africa: strategies to achieve the 2030 elimination targets. Lancet Gastroenterol Hepatol. 2017;2(12):900-909.

3. World Health Organization. Combating hepatitis B and $\mathrm{C}$ to reach elimination by 2030: advocacy brief. Geneva: World Health Organization; 2016.

4. World Health Organization. Global health sector strategy on viral hepatitis 2016-2021. Towards ending viral hepatitis. Geneva: World Health Organization; 2016.

5. Qureshi H, Bile KM, Jooma R, et al. Prevalence of hepatitis B and C viral infections in Pakistan: findings of a national survey appealing for effective prevention and control measures. East Mediterr Health J. 2010;16 Suppl:S15-S23.

6. Hamid S, Umar M, Alam A, et al. PSG consensus statement on management of hepatitis C virus infection-2003. J Pak Med Assoc. 2004;54(3):146.

7. Waheed Y, Shafi T, Safi SZ, et al. Hepatitis C virus in Pakistan: a systematic review of prevalence, genotypes and risk factors. World Journal of Gastroenterology: WJG. 2009;15(45):5647.

8. Xu R, Zhang Z, Wang FS. Liver fibrosis: mechanisms of immunemediated liver injury. Cell Mol Immunol. 2012;9(4):296-301. 
9. Seeff LB. Natural history of chronic hepatitis C. Hepatology. 2002;36(5B):S35-S46.

10. Schuppan D, Afdhal NH. Liver cirrhosis. The Lancet. 2008;371(9615):838851.

11. Watson JP, Brind AM, Chapman CE, et al. Hepatitis C virus: epidemiology and genotypes in the north east of England. Gut. 1996;38(2):269-276.

12. Hassoun Z, Willems B, Deslauriers J, et al. Assessment of fatigue in patients with chronic hepatitis C using the fatigue impact scale. Dig Dis Sci. 2002;47(12):2674-2681.
13. Toyoda H, Kumada T, Kiriyama S, et al. Influence of age, sex, and degree of liver fibrosis on the association between serum alanine aminotransferase levels and liver inflammation in patients with chronic hepatitis C. Dig Dis Sci. 2004;49(2):295-299.

14. Nadeem A, Hussain MM, Aslam M. Correlation of serum alanine aminotransferase and aspartate aminotransferase levels to liver histology in chronic hepatitis C. J Coll Physicians Surg Pak. 2010;20(10):657-651.

15. AASLD/IDSA HCV Guidance Panel. Hepatitis C guidance: AASLDIDSA recommendations for testing, managing, and treating adults infected with hepatitis C virus. Hepatology. 2015;62(3):932-954. 